NASA Technical Memorandum 101420

\title{
Advanced Core Technology: Key to Subsonic Propulsion Benefits
}

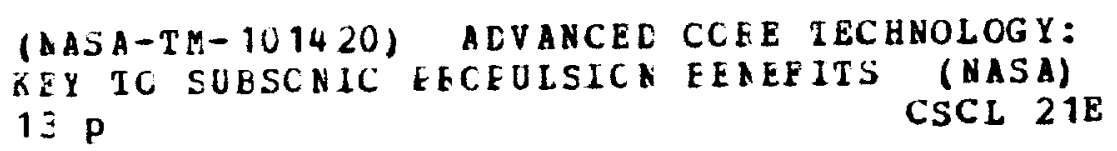

Arthur J. Glassman, Christopher A. Snyder, and Gerald Knip, Jr.

Lewis Research Center

Cleveland, Ohio

Prepared for the

34th International Gas Turbine and Aeroengine Congress and Exposition sponsored by the American Society of Mechanical Engineers

Toronto, Canada, June 4-8, 1989 


\title{
ADVANCEO CORE TECHNOLOGY: KEY TO SUBSONIC PROPULSION BENEFITS
}

\author{
Arthur 3. Glassman, Christopher A. Snyder, and Gerald Knip, Jr. \\ National Aeronautics and Space Administration \\ Lewis Research Center \\ Cleveland, ohio 44135
}

ABSTRACT

A study was conducted to identify the potential performance benefits and key technology drivers associated with advanced cores for subsonic high-bypass turbofan engines. Investigated first were the individual sensitivities of varying compressor efficiency, pressure ratio and bieed (for turbine cooling); combustor pressure recovery; and turbine efficiency and inlet temperature on thermal efficiency and core specific power output. Then, engine cycle and mission performance benefits were determined for systems incorporating all potentially achievable technology advancements.

The individual thermodynamic sensitivities are shown over a range of turbine temperatures (at cruise) from 2900 to $3500^{\circ} \mathrm{R}$ and for both constant (current technology) and optimum (maximum thermal efficiency) overall pressure ratios. It is seen that no single parameter by itself will provide a large increase in core thermal efficiency, which is the thermodynamic parameter of most concern for transport propulsion. However, when all potentially achievable advancements are considered, there occurs a synergism that produces significant cycle and mission performance benefits. The nature of these benefits are presented and the technology challenges associated with achieving them are discussed.

\section{INTROOUCTION}

Over the past 50 years since the advent of the Whittle engine, the performance of aircraft gas turbine engines has improved dramatically. For subsonic commer. cial transport engines, this performance improvement is shown in Fig. 1 in terms of overall cruise efficiency and its component parts, thermal efficiency and propulsive efficiency. The low-spool energy transmission efficiency is herein included as part of the propulsive efficiency. The thermal efficiency of the whittle engine was quite low due to its low pressure ratio and low turbine temperature. These same features, however, provided a moderately high propulsive efficiency due to the low jet velocity.

By the time the first commercial turbojet engine came along, improvements in materials and component derodynamics resulted in more than doubling the thermal efficiency. Continued improvements in materials and component technologies, including the introduction of turbine cooling, led to still further thermal efficiency gains in addition to the propulsive efficiency gains provided by the low- and high-bypass turbofans currently in service. Also shown in Fig. 1 is the advanced turboprop, expected to enter service in the early 1990's, with its very high propulsive efficiency.

As we look to the future, we can speculate that higher-bypass turbofans will be able to provide higher propulsive efficiencies perhaps approaching those of the turboprop. Can we also hope to achieve further improvements in thermal efficiency and where might these gains be found? To try to answer these questions, analyses were performed to identify the key drivers. Investigated first were the individual sensitivities of varying compressor efficiency, pressure ratio, and bleed (for cooling the turbine): combustor pressure recovery; and turbine efficiency and inlet temperature on thermal efficiency and core specific power output. Then, engine cycle and mission performance benefits were determined for systems incorporating all potentially achievable technology advancements.

This paper presents the results of these analyses. The individual thermodynamic sensitivities are shown over a range of turbine temperatures from 2900 to $3500^{\circ} \mathrm{R}$ and for both constant and optimum (maximum thermal efficiency) overall pressure ratios. Also shown are the effects of coupling both core and low-spool/nacelle technology advancements on engine cycle and mission performance. Finally, the technology challenges associated with achieving these performance improvements are discussed.

\section{CORE SENSITIVITY ANALYSIS}

A sensitivity analysis of engine core thermodynamic parameters was performed to identify the potential of individual technology advancements to yield engine cycle performance improvements. The engine cycle model and assumptions used for the analysis and the resultant sensitivities of thermal efficiency and core specific power output are presented in this section. 


\section{ORIGINAL PAGE IS OF POOR QUALITY}

The engine cycle model used for the sensitivity analysis is shown in Fig. 2. A three-spool turboshaft engine was used as the computational model for obtaining engine core performance. A loss-free power turbine on a free spool was used as an artifice to obtain core performance from computed engine performance. Core thermal efficiency is herein defined as the ideal power available from the engine core (i.e., the output from the ideal power turbine) as a fraction of fuel heating power. The pressure ratio across the power turbine was adjusted so the core stream would produce no net

thrust. The supercharger of the cycle model represents the compression provided by the inner (i.e., core) section of a fan or by a low-spool compressor, whlle the low-spool turbine provides only the power needed by the supercharger.

Engine inlet conditions for this analysis were a Aach number of 0.8 and an altitude of $35000 \mathrm{ft}$. Component baseline parameters are shown on Fig. 2. All turcomachine efficiencies are adiabatic except for the ole compressor efficiency, which is polytropic. Sensitivity analyses were performed at four turbine inlet temperatures $\left(2900,3100,3300\right.$, and $\left.3500{ }^{\circ} R\right)$ for both constant $(O P R=37$ ) and optimum (maximum therma) efficiency $O P R=57,72,87$, and 106 , respectively) overa 11 pressure ratio. These sensitivity analysis reference noints along with the computed thermal efficiencies are shown in Fig. 3. Cycle parameter sensitivities were letermined around each of the eight points. The sensirivities of core thermal efficiency and specific power utput to variations in compressor efficiency, pressure atio, and bleed (for turbine cooling); combustor presure recovery: and turbine efficiency and inlet temperaure were determined. The range of variations used to determine the sensitivities were on the order of plus and minus several percent.

The sensitivity analysis provided 12 sets of curves such as those in Fig. 4, which shows the sensitivities of core thermal efficiency and specific power output to ariations in core compressor efficiency for four turbine inlet temperatures and a constant overall pressure atio. For the limited range of parameter variations studied, the sensitivities were all approximately linear. Thus, average sensitivities of core thermal effi. riency and specific power output were determined as Shown in Fig. 5 for constant overall pressure ratio of 37 and in $\mathrm{Fig} .6$ for optimum overall pressure ratio 1 .e. at maximum thermal efficiency).

The six independent parameters for which the sensi- ivities were determined are shown at the bottoms of the bars. At the tops of the bars are the units for apressing the sensitivities. The plus or minus sign inside the bar represents the direction of the sensitivity slope. The gray area, where it exists, at the top of a bar shows the effect of turbine inlet temperature in the sensitivity. In all cases, except for the effect f OPR on thermal efficiency at constant pressure ratio, where the reverse is true, the top of the gray area is for 2900 o $R$ while the bottom of the gray area is for $3500^{\circ} \mathrm{R}$. No gray area at the top of a bar indicates the absence of a temperature dependency.

From Figs. 5 and 6 we see that thermal efficiency and/or specific power benefits are avallable to some axtent from all the cycle and component parameters studied. Burner pressure recovery does not offer much potential benefit because of the relatively small sensitivities and the high values, better than 95 percent lready being achieved. The sensitivities to turbine and compressor efficiencies are higher, about twice as high, at optimum pressure ratio than at the constant oressure ratio. This occurs because output power is becoming a smaller difference between two larger work terms as pressure ratio increases. Turbine inlet temperature affects specific power considerably more than it does thermal efficiency. So does compressor bleed since increasing bleed is effectively the same as reducing turbine inlet temperature.

Both thermal efficiency and specific power display maximum values as pressure ratio varies, the pressure ratio for maximum thermal efficiency being much higher than that for maximum specific power. As seen from the sensitivity slope directions indicated in Fig. 5, the constant overall pressure ratio of 37 is greater than that for maximum specific power but less (also see Fig. 4) than for maximum thermal efficiency. Thus, increasing pressure ratio from current values offers increased thermal efficiency but at the expense of reduced specific power. Since thermal efficiency is of primary importance for subsonic transport propulsion systems, increased pressure ratio should be explored. However, it should be noted that there is no single parameter that by itself will provide a large increase in thermal efficiency.

\section{ENGINE CYCLE ANO MISSION PERFORMANCE}

Performance improvements for the core, low spool and nacelle, engine, and mission that result from the coupling of potentially achievable technology advancements are addressed in this section. The effect of advanced core technology on improvements in core thermal efficiency and core specific power output are presented in Figs. 7 and 8 , respectively. An engine entering service in 1987 is the baseline for the improvements.

From Fig. 7 we see that, with current turbine temperature and component technology, increasing the overall pressure ratio yields only a small potential

improvement in core thermal efficiency (about 2-1/2 percent at a pressure ratio of 60) primarily because of the increasing turbine cooling flow requirement. If the need for cooling can be eliminated through advanced materials technology, then the potential improvement in thermal efficiency reaches about 7 percent at an overall pressure ratio of 80 . The uncooled turbine is herein used to represent the limit of what can be achieved through advancement in materials and cooling technologies. With improved efficiencies for the core compressor and turbine, the thermal efficiency improvement increases to 14 to 18 percent at a pressure ratio of about 100. The cross-hatched band in Fig. 7 represents varying degrees of optimism concerning component efficiency improvements. These component efficiency gains would come not only from aerodynamics improvements, but also from the higher rotative speeds and reduced Teakages enabled by technology advancements in materials, structures, bearings, and seals. Finally, if uncooled turbine temperature can increase to 3460 or, further small improvements in thermal efficiency are thermodynamically achievable, but require very high pressure ratios, values beyond 100 .

A major point to be drawn from Fig. 7 is that neither pressure ratio by itself, advanced component technology by itself nor turbine temperature by itself provides a large increase in thermal efficiency. However, increasing the engine overall pressure ratio enables significant improvements to be made through synergistic coupling with increased turbomachine efficiencies, reduced cooling bleed, and increased turbine temperature. Through this synergism, the thermal efficiency improvement is at least double that which would be determined from a linear combination of individual improvements. 
As the sensitivity analys is showed, core specific power output is strongly dependent on turbine temperature. Figure 8 , which presents the changes in core specific power with advanced core technology, displays a band to show the specific power required for ultra-highbypass turbofans capable of providing large improvements in propulsive efficiency without excessive engine size and weight. As seen, turbine temperatures on the order of $3460^{\circ} R$ are needed to meet these power requirements because the core flow will be 5 percent or less of the total air flow.

The potential benefits of advanced low-spool and nacelle technologies are shown in Fig. 9. The top curve is for the idealized case of no nacelle loss and reflects the increasing propulsive efficiency with decreasing fan pressure ratio. With current technology nacelle losses included, one obtains the bottom curve, which shows that the nacelle losses more than offset the increases in propulsive efficiency as bypass ratio and engine diameter increase. For advanced nacelle technology (i.e., short thin streamlined contour), performance is improved to the cross-hatched band. Finally, the dashed curve represents the inclusion of a 3 percent gain in fan efficiency (with respect to the top of the band). On the basis of this analysis of the impact of low-spool and nacelle technology advancements, it appears that an 8 to 10 percent reduction in SFC is achievable.

Combining the core and low-spool/nacelle potential benefits for a 490-passenger transport flying $5000 \mathrm{nmi}$ yields benefits in fuel and direct operating cost (OOC) as shown in $\mathrm{Fig}$. 10. The bars indicate the 16 to 19 percent improvement in SFC from core technology, as shown in Fig. 7 , and the 8 to 10 percent improvement in SFC from low-spool technology. In terms of mission performance, the overall potential savings of fuel is 35 to 40 percent with a 10 to 12 percent reduction in DOC. Note that two-thirds of the savings is directly attributable to core performance improvements.

\section{TECHNOLOGY CHALLENGES}

Achievement of the aforementioned performance benefits requires advanced core technology that presents challenges across the spectrum of engine disciplines. The impact of very high core pressure ratio on the engine compression system is shown in Fig. 11 . Shown here is the effect of increasing pressure ratio on gas temperature, corrected flow rate and passage height for a standard-day inlet flow rate of $75 \mathrm{lb} / \mathrm{sec}$. The need for advanced compressor materials is noted. Advanced lightweight materials, such as titanium and iron aluminides, are candidates for the rear of the compressor. The reductions in corrected flow rate and, consequently, passage height bring the rear end of the compressor into the realm of small engine technology. Radial machines, either in-line or as an off-axis spool, can be considered for use here. In addition, aerodynamic technology efforts are required to address the desires for higher turbomachine efficiencies and for increased stage loadings to reduce the overall number of stages.
Another challenge is that of efficient sustained cruise operation at temperatures on the order of $3460^{\circ} \mathrm{R}$. While the elimination of turbine cooling would be most desirable from the standpoint of thermodynamic performance, it is unlikely that this will be achieved in the foreseeable future for commercial transport engines operating at $3460^{\circ} \mathrm{R}$. However, a combination of advanced turbine materials and cooling technologies can be used to reduce turbine cooling flow requirements to values incurring only small performance penalties. Shown in Fig. 12 is the chronological trend for turbineblade-material temperature covering both past history and future projections. Evolutionary progress offers continuing small increases in allowable temperature while the introduction of new metallic and/or ceramic materials systems, when they occur, will result in large jumps in temperature capability. Turbine cooling effectiveness trends are shown in Fig. 13. Early cooling configurations performed with an effectiveness of about 40 percent and this has now increased to about 60 percent. Advanced concepts to increase effectiveness to 70 percent and beyond are being explored.

These are the more obvious technology challenges. Less obvious, but nonetheless important, are the structural, mechanical, and controls technology advances needed to make innovative ultra-high-bypass turbofan engine concepts a reality.

\section{CONCLUDING REMARKS}

A study was conducted to identify the potential performance benefits and key technology drivers associated with advanced cores for subsonic high-bypass turbofan engines. There is no single parameter that by itself will provide a large increase in core therma? efficiency, which is the thermodynamic parameter of most concern for transport propulsion. However, increasing the engine overall pressure ratio enables significant performance improvements to be achieved through synergistic coupling with increased turbomachine efficiencies, reduced turbine cooling and increased turbine temperature. For a long-range transport mission, technology advancements can provide a 35 to 40 percent reduction in fuel used and an associated 10 to 12 percent reduction in direct operating cost (DOC). Twothirds of this savings is directly attributable to core technology advancements. Thus, advanced core technology is the key to substantial performance improvements for the subsonic transport of the future.

Achieving the efficiency goals shown in Fig. 14 will require dedicated efforts to advance technologies across the spectrum of engine disciplines. The very high pressure ratios will challenge compressor aerodynamics as well as compressor materials. Sustained efficient operation at higher turbine temperatures will require advancements in turbine materials and cooling technologies. Innovative concepts will undoubtedly be a key contributor to the successful achievement of highefficiency, high-pressure-ratio high-temperature ultrahigh-bypass engines.

\section{ORIGNAL PAGE IS OF POOR QUALITY}




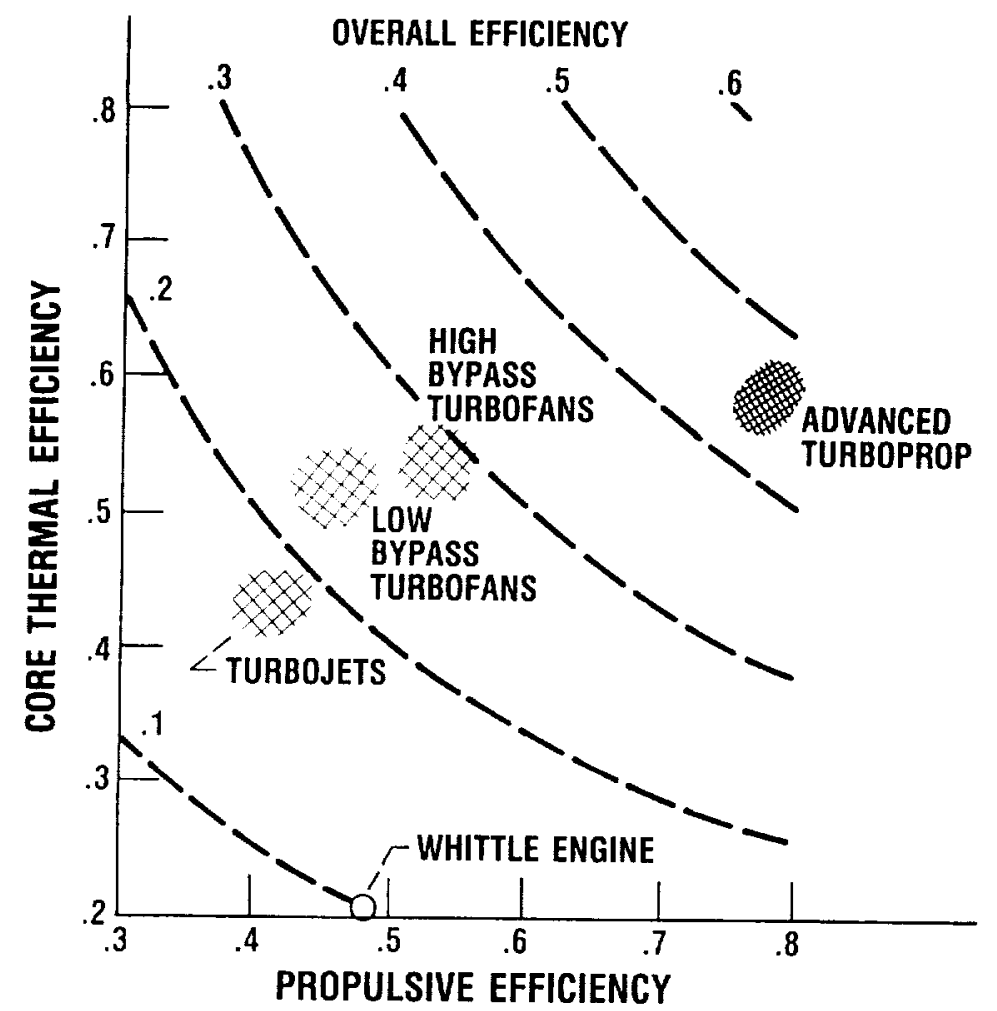

FIGURE 1. - EFFICIENCY TRENDS FOR COMMERCIAL TURBINE ENGINES.

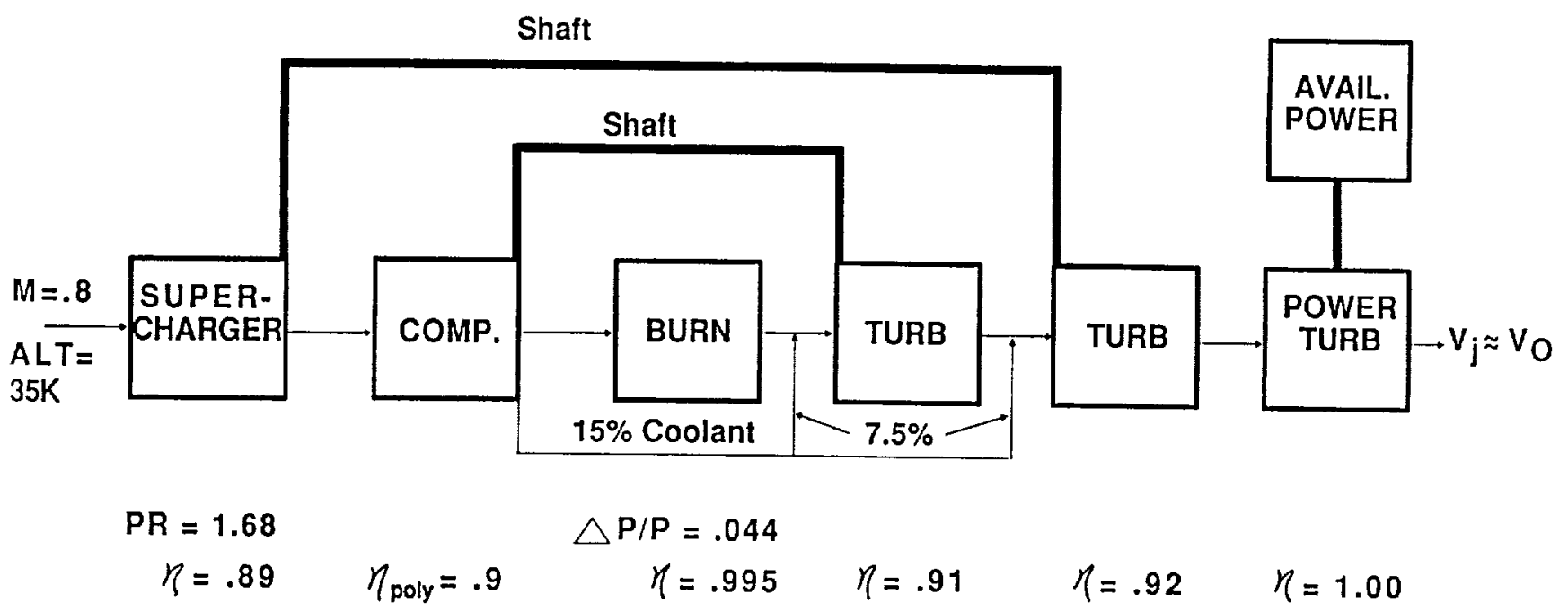

FIGURE 2. - BASELINE ENGINE CYCLE MODEL FOR SENSITIVITY ANALYSIS. 


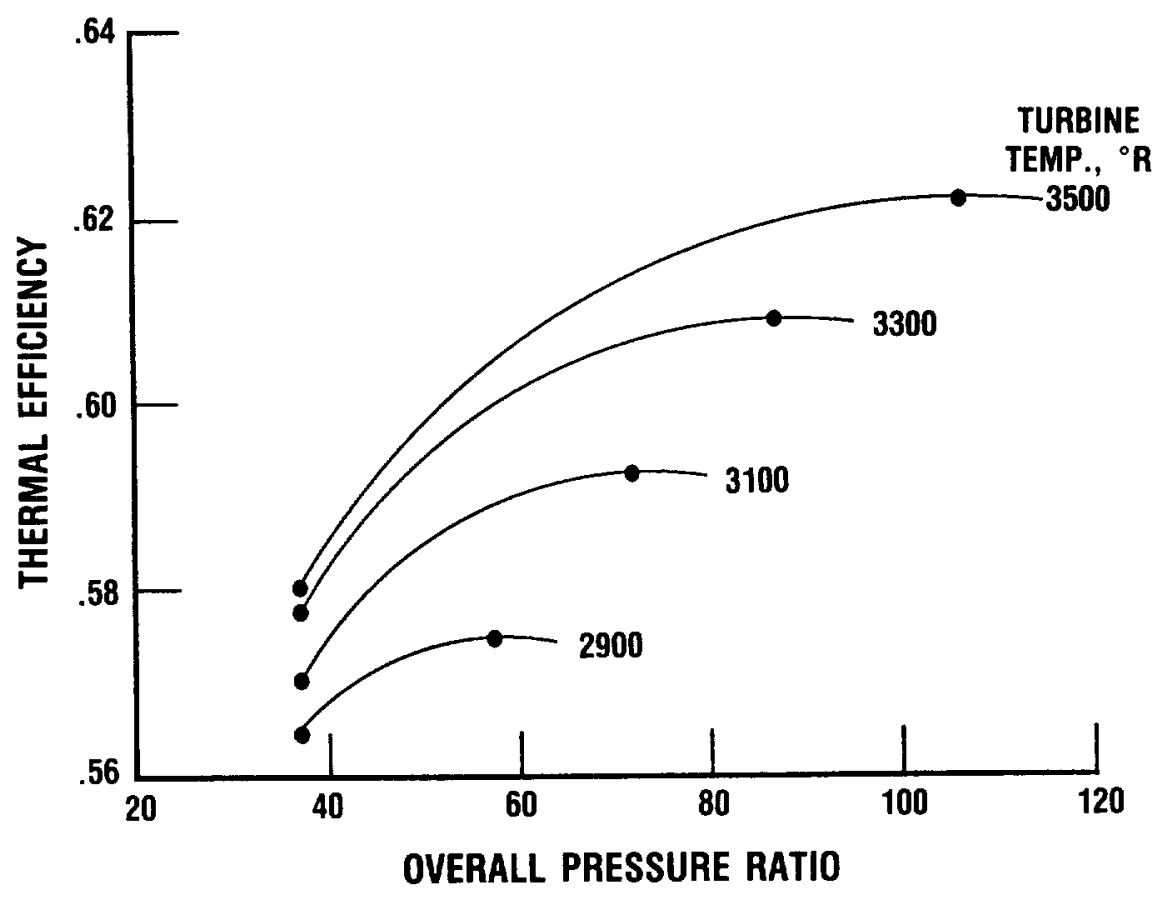

FIGURE 3. - SENSITIVITY ANALYSIS REFERENCE POINTS. 

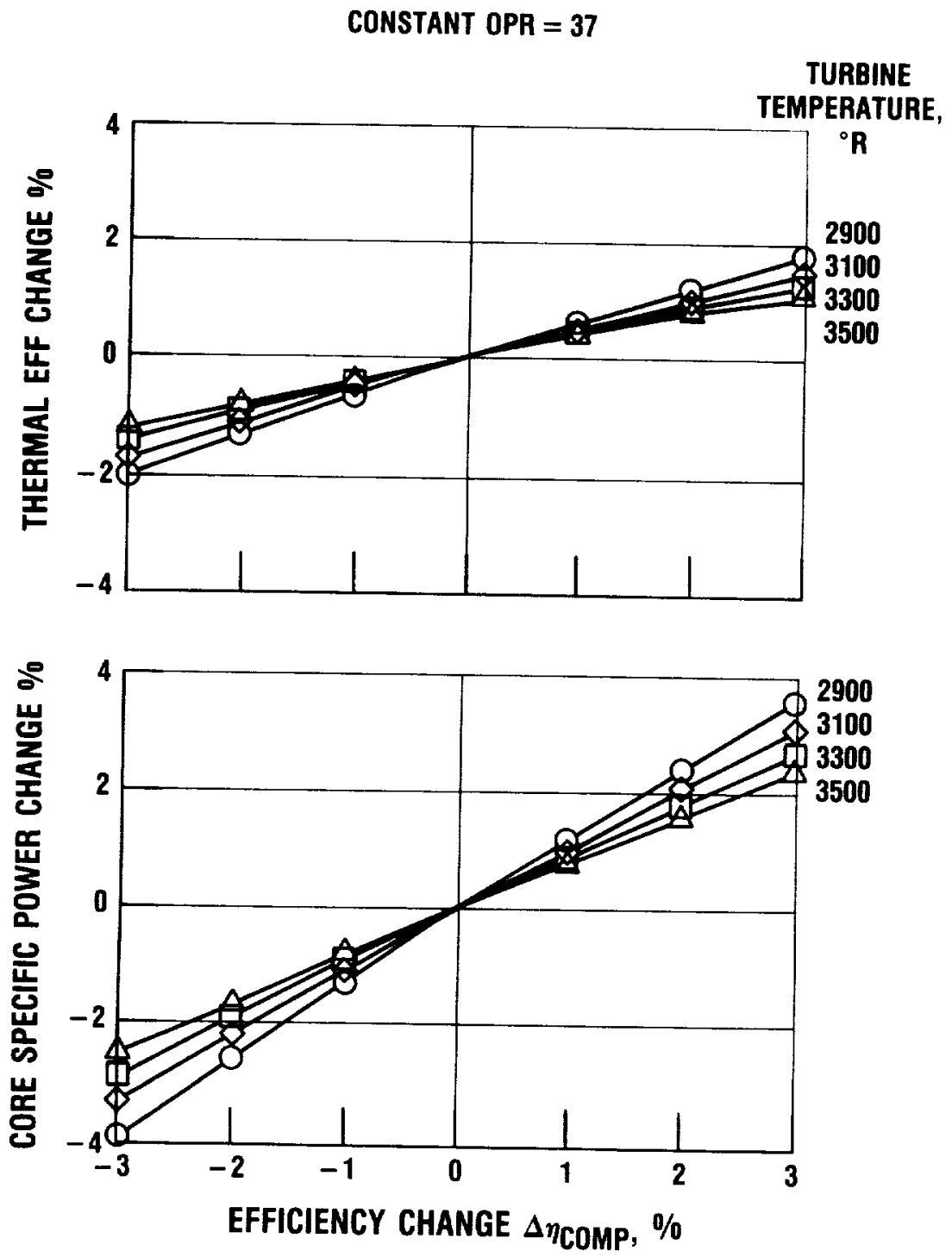

FIGURE 4. - EFFECT OF COMPRESSOR EFFICIENCY ON CORE ENGINE PERFORMANCE. 
THERMAL EFFICIENCY

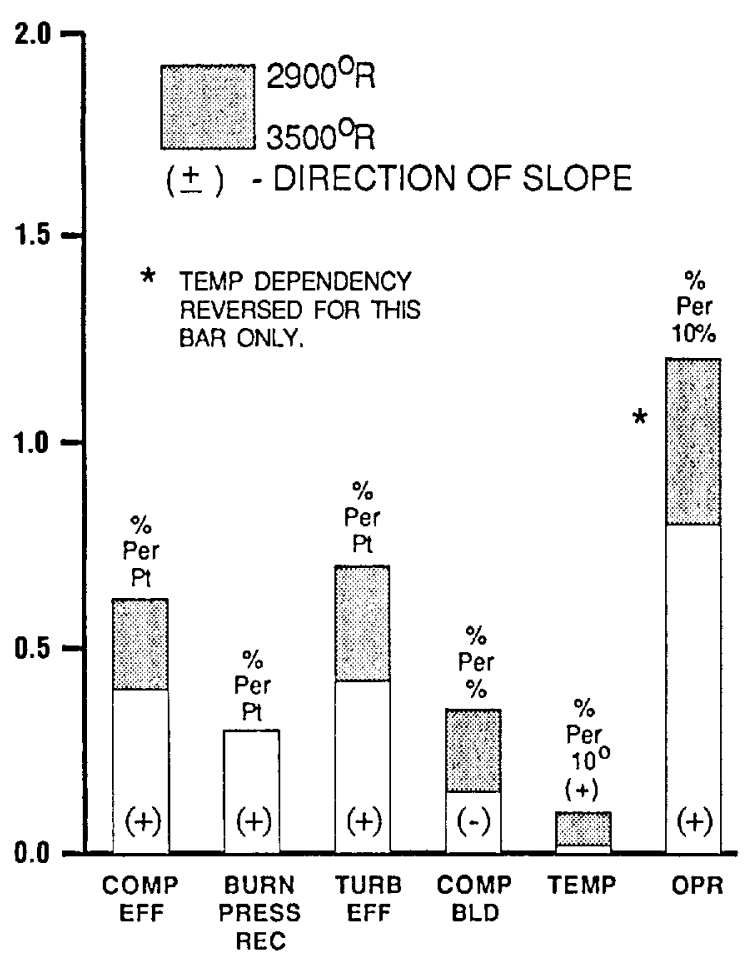

CORE SPECIFIC POWER

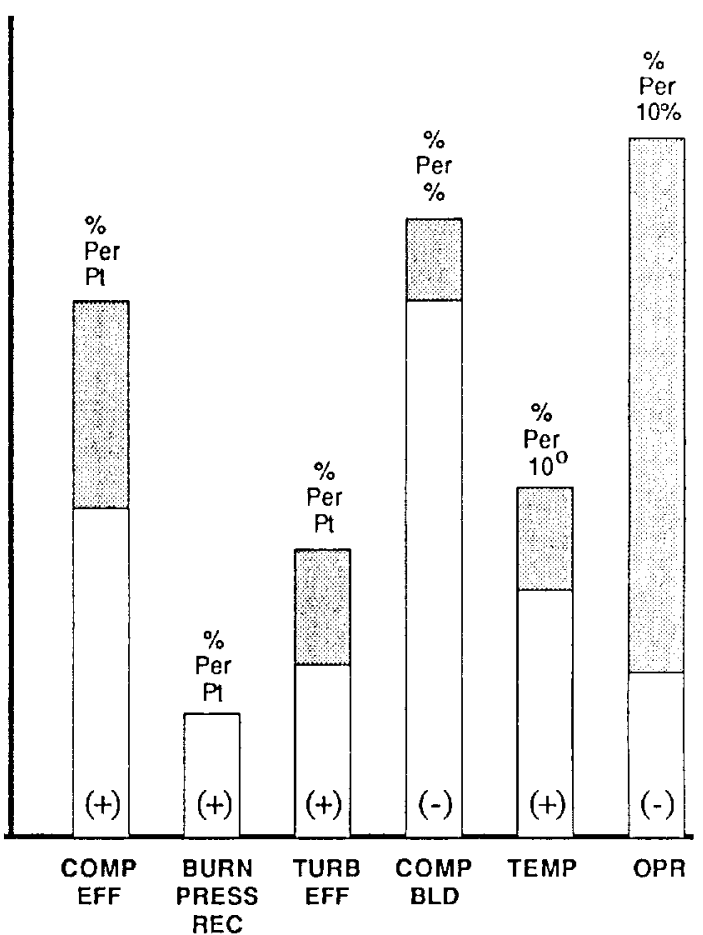

FIGURE 5. - ENGINE CORE SENSITIVITIES FOR CONSTANT OPR.

THERMAL EFFICIENCY

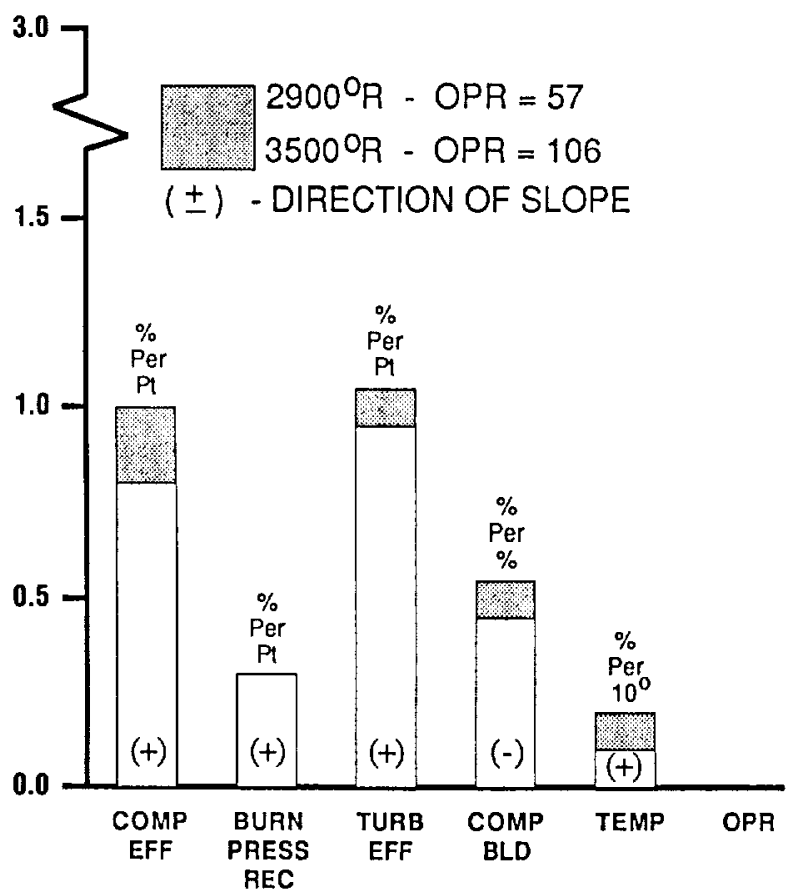

CORE SPECIFIC POWER $\%$

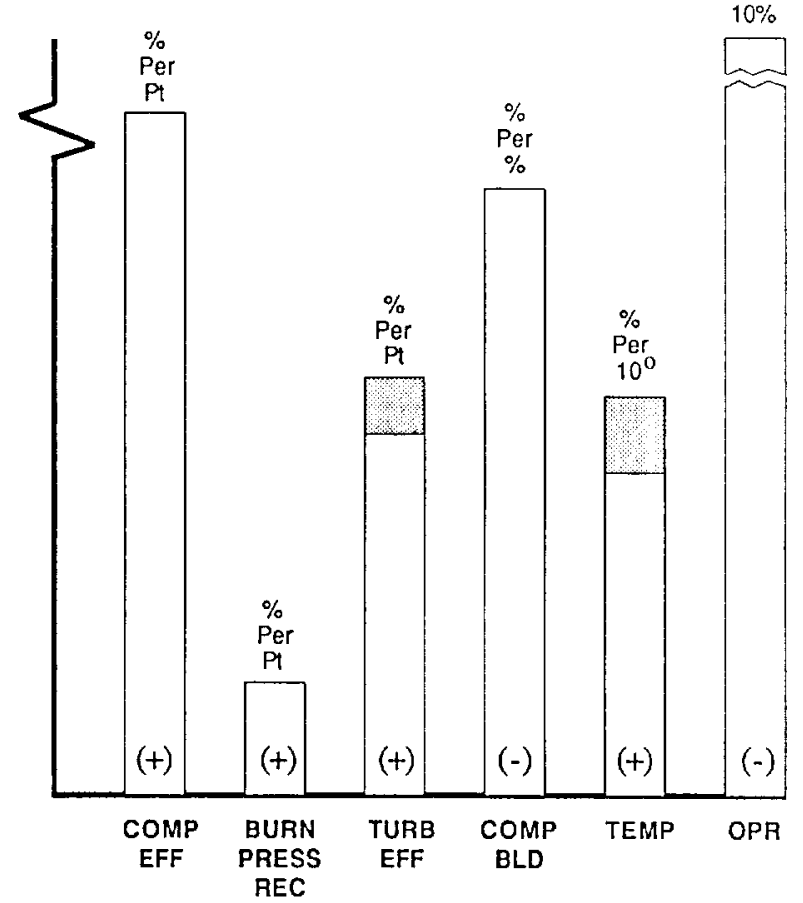

FIGURE 6. - ENGINE CORE SENSITIVITIES FOR OPTIMUM OPR. 


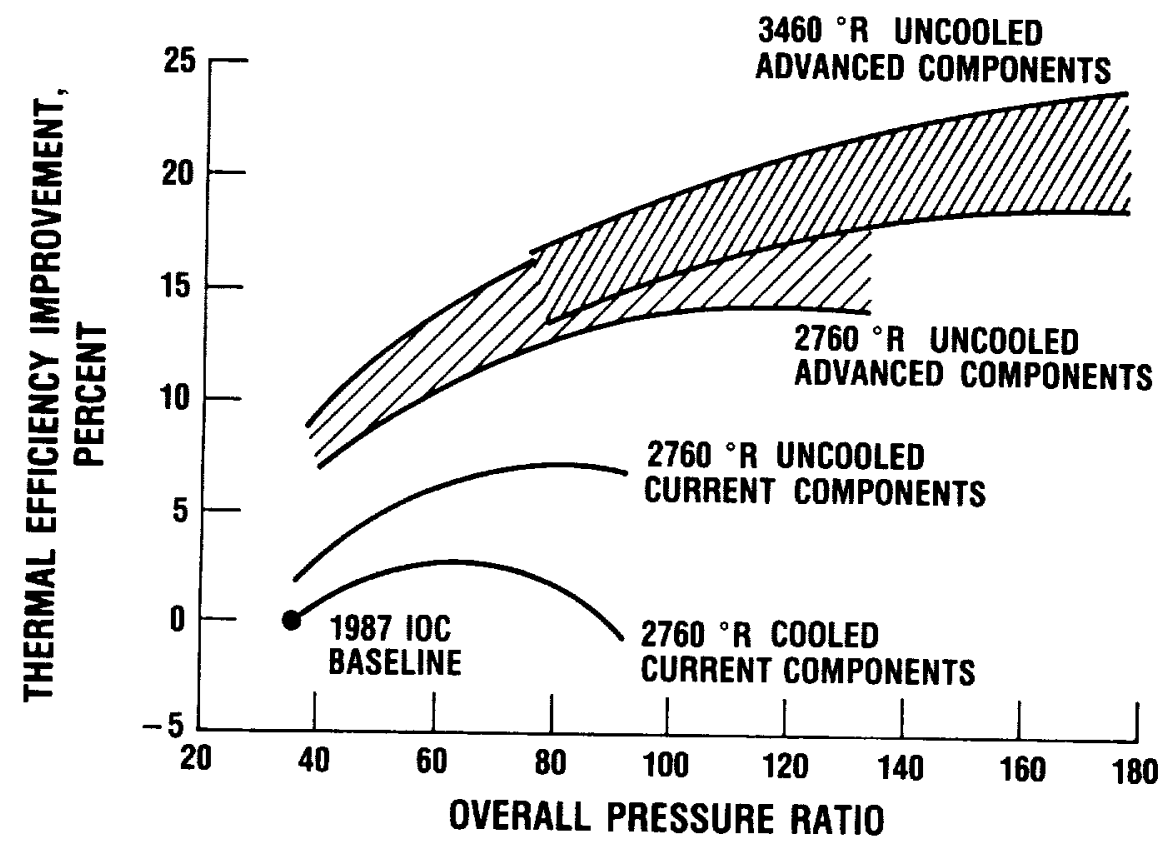

FIGURE 7. - EFFECT OF CORE TECHNOLOGY ON THERMAL EFFICIENCY.

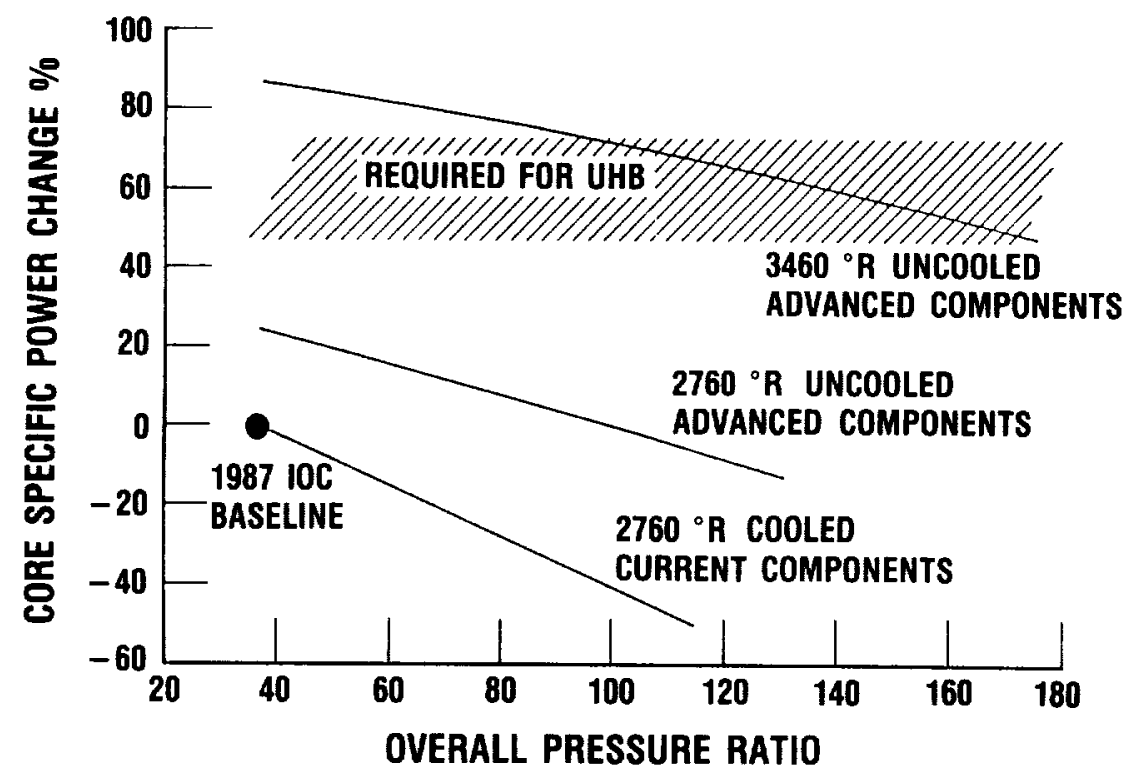

FIGURE 8. - EFFECT OF CORE TECHNOLOGY ON CORE SPECIFIC POWER OUTPUT. 


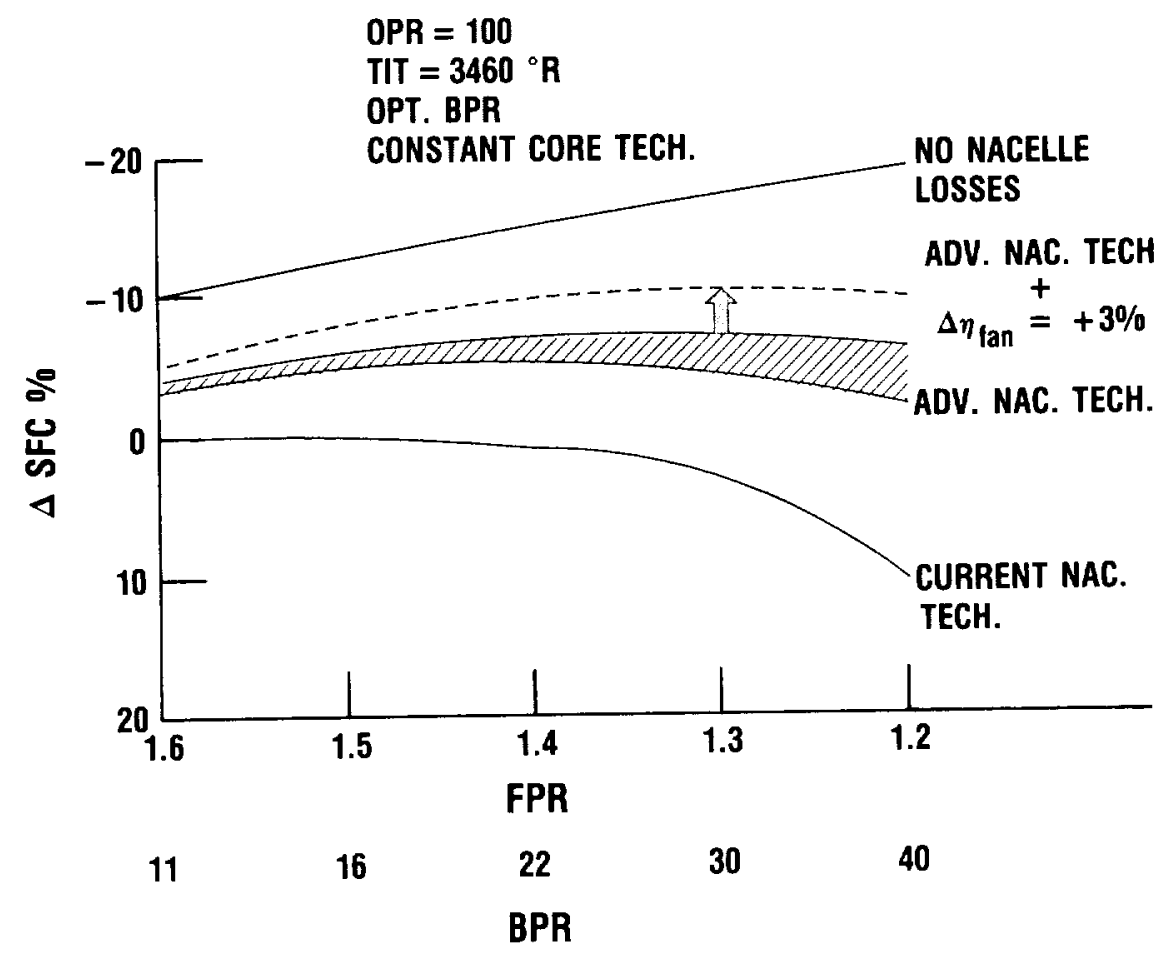

FIGURE 9. - EFFECT OF LOW-SPOOL AND NACELLE TECHNOLOGIES.

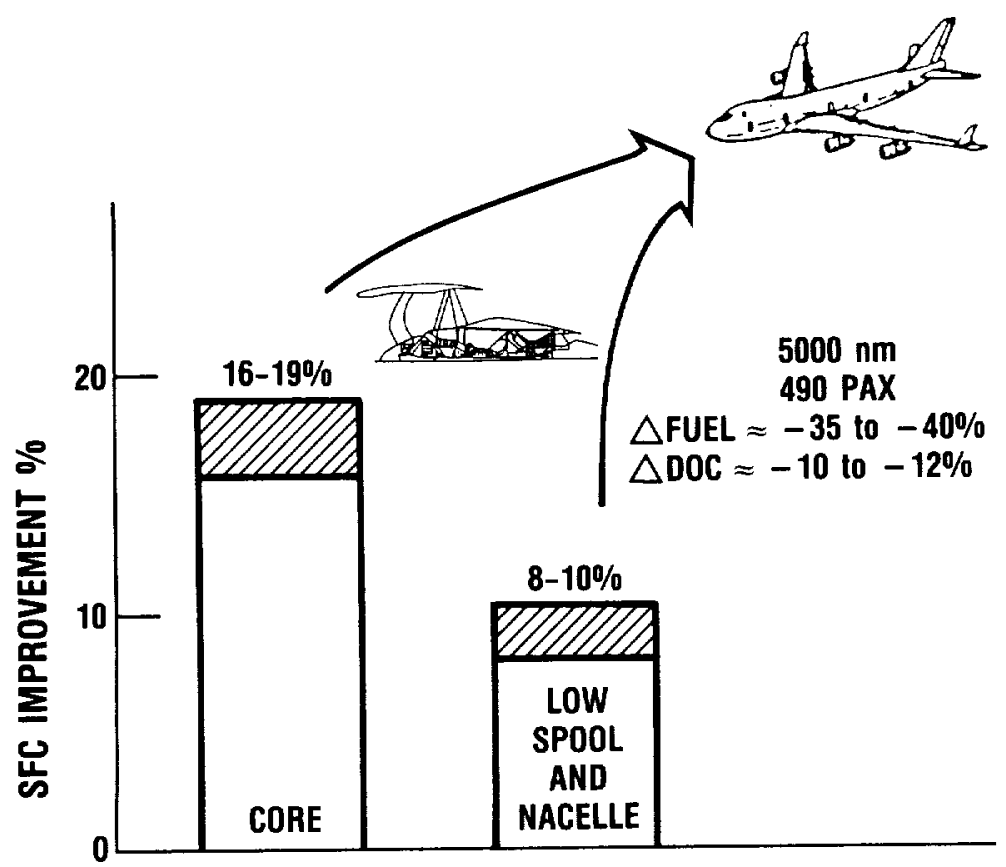

FIGURE 10. - MISSION BENEFITS OF ADVANCED TECHNOLOGIES. 


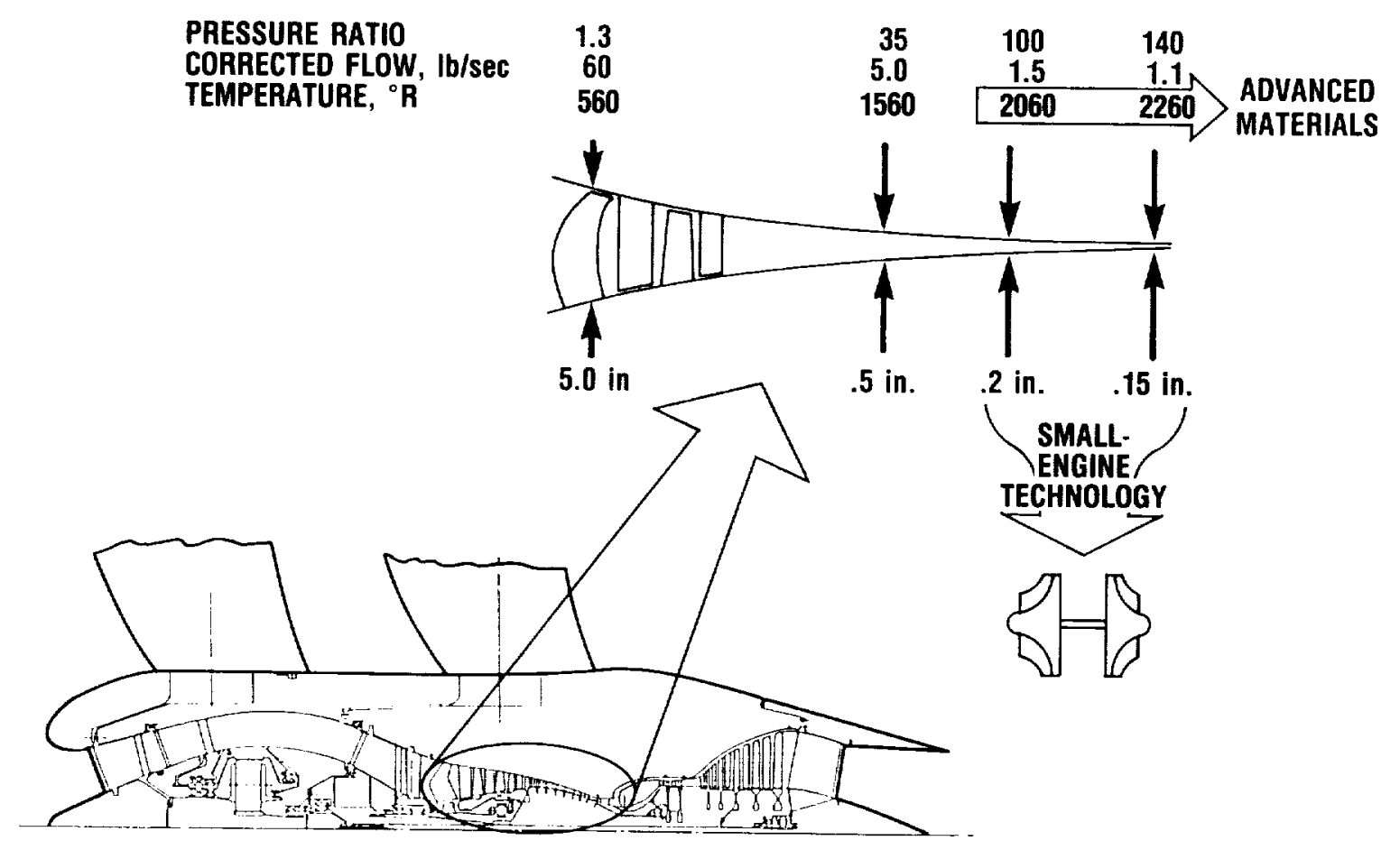

FIGURE 11. - IMPACT OF VERY HIGH CORE PRESSURE RATIO.

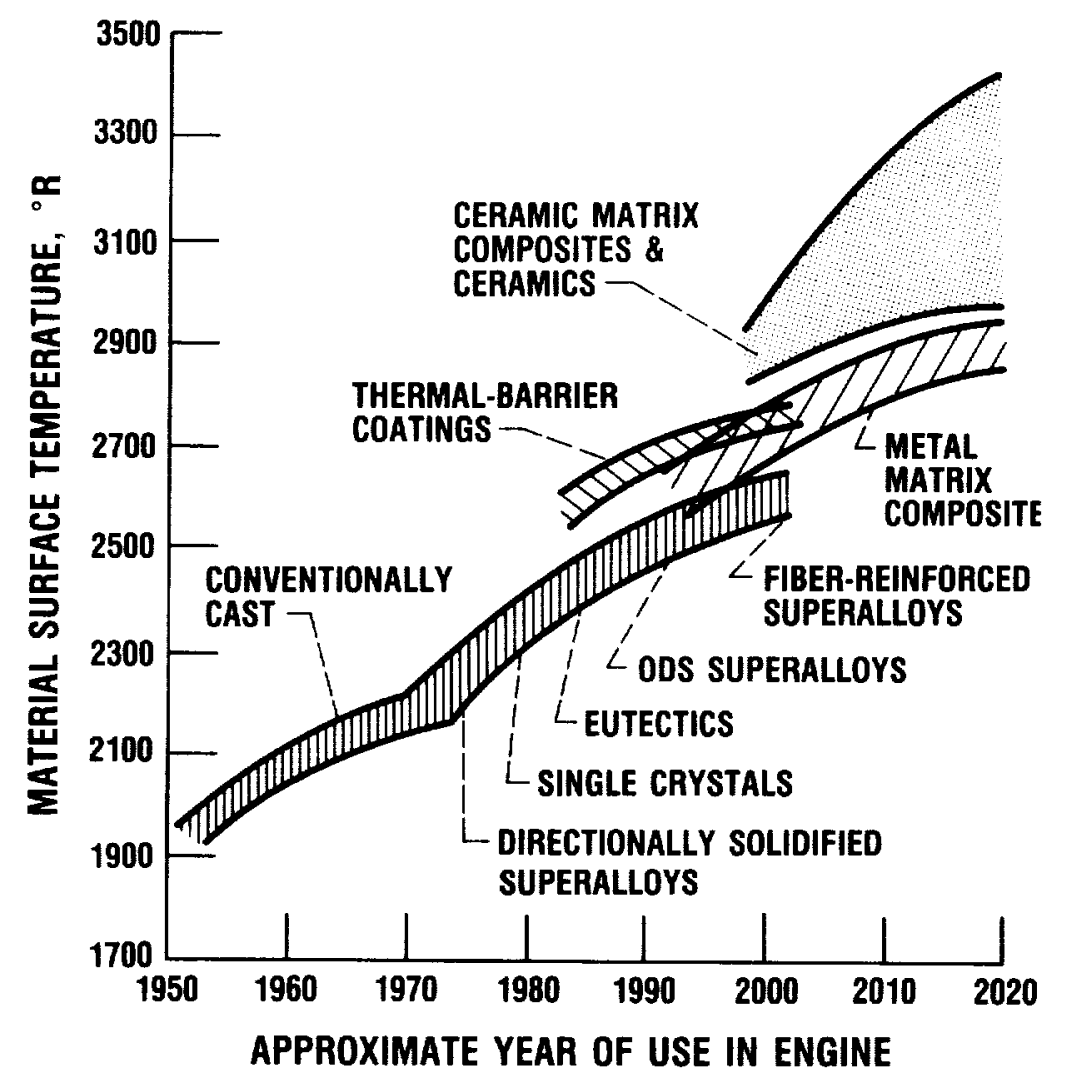

FIGURE 12.- TURBINE BLADE MATERIALS TRENDS. 


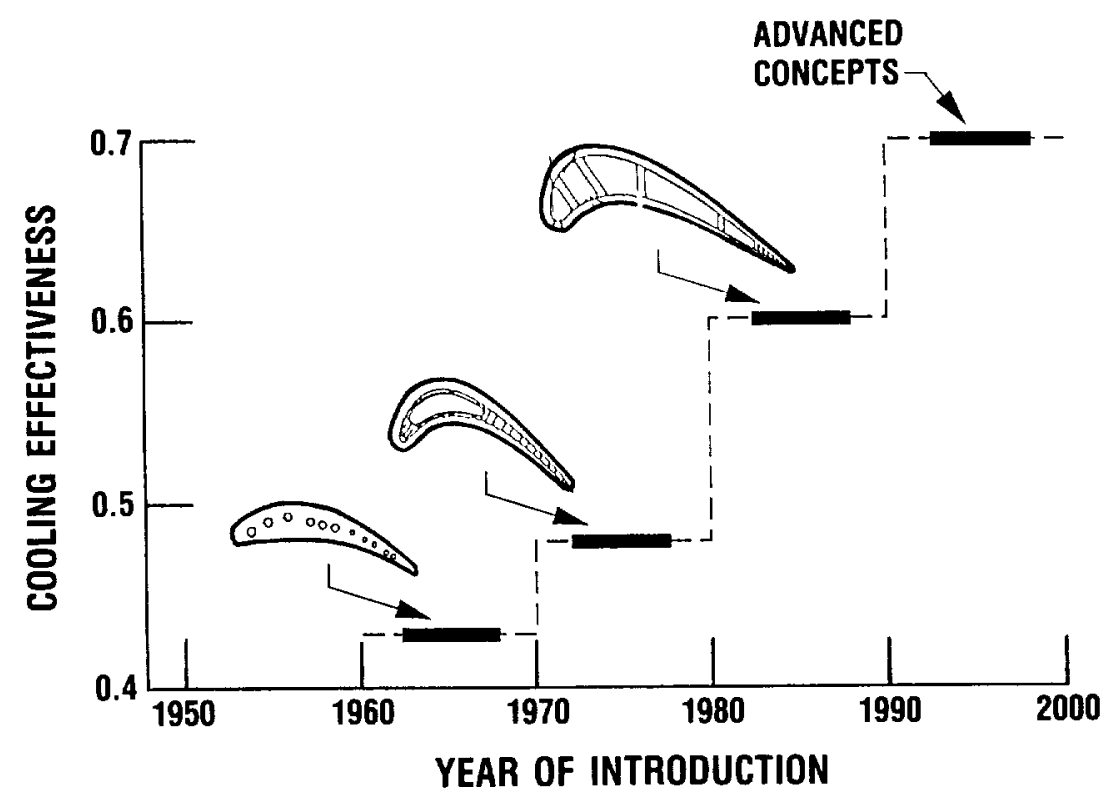

FIGURE 13. - TURBINE COOLING TECHNOLOGY TRENDS.

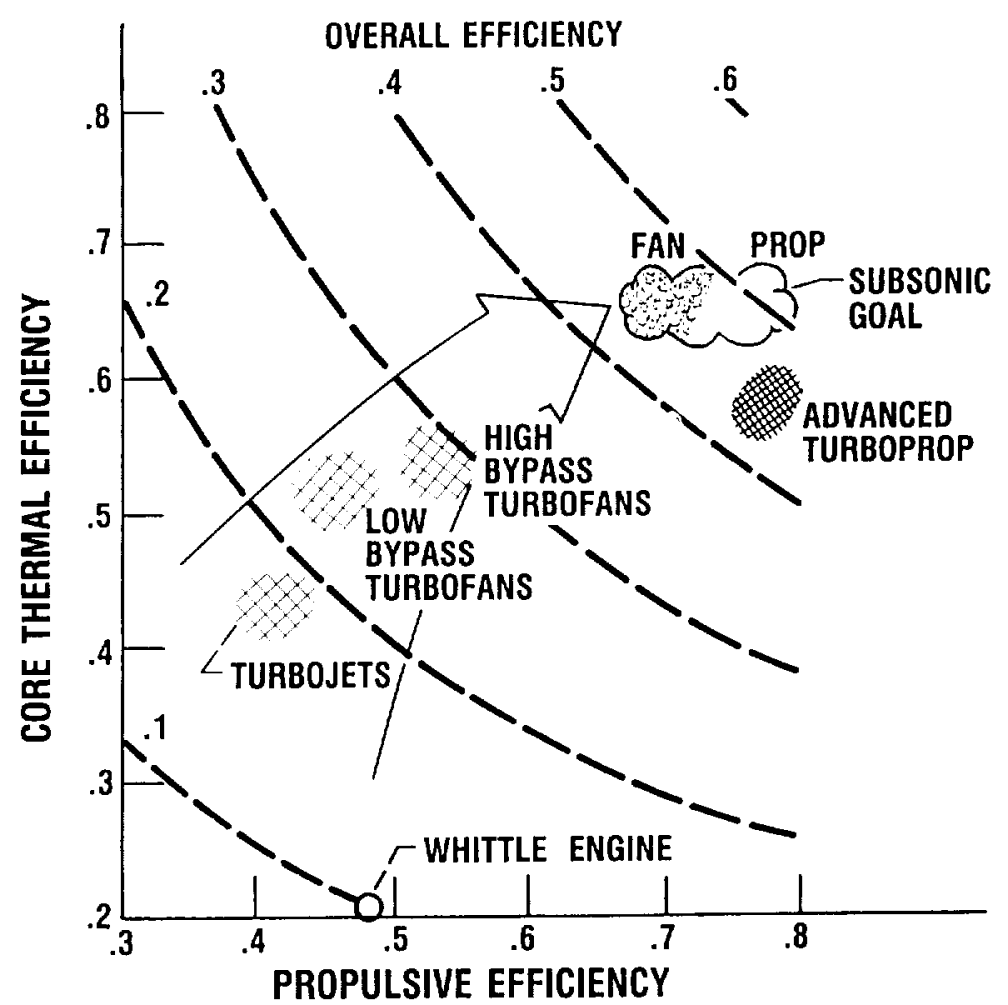

FIGURE 14. - FUTURE COMMERCIAL ENGINE EFFICIENCY GOALS. 


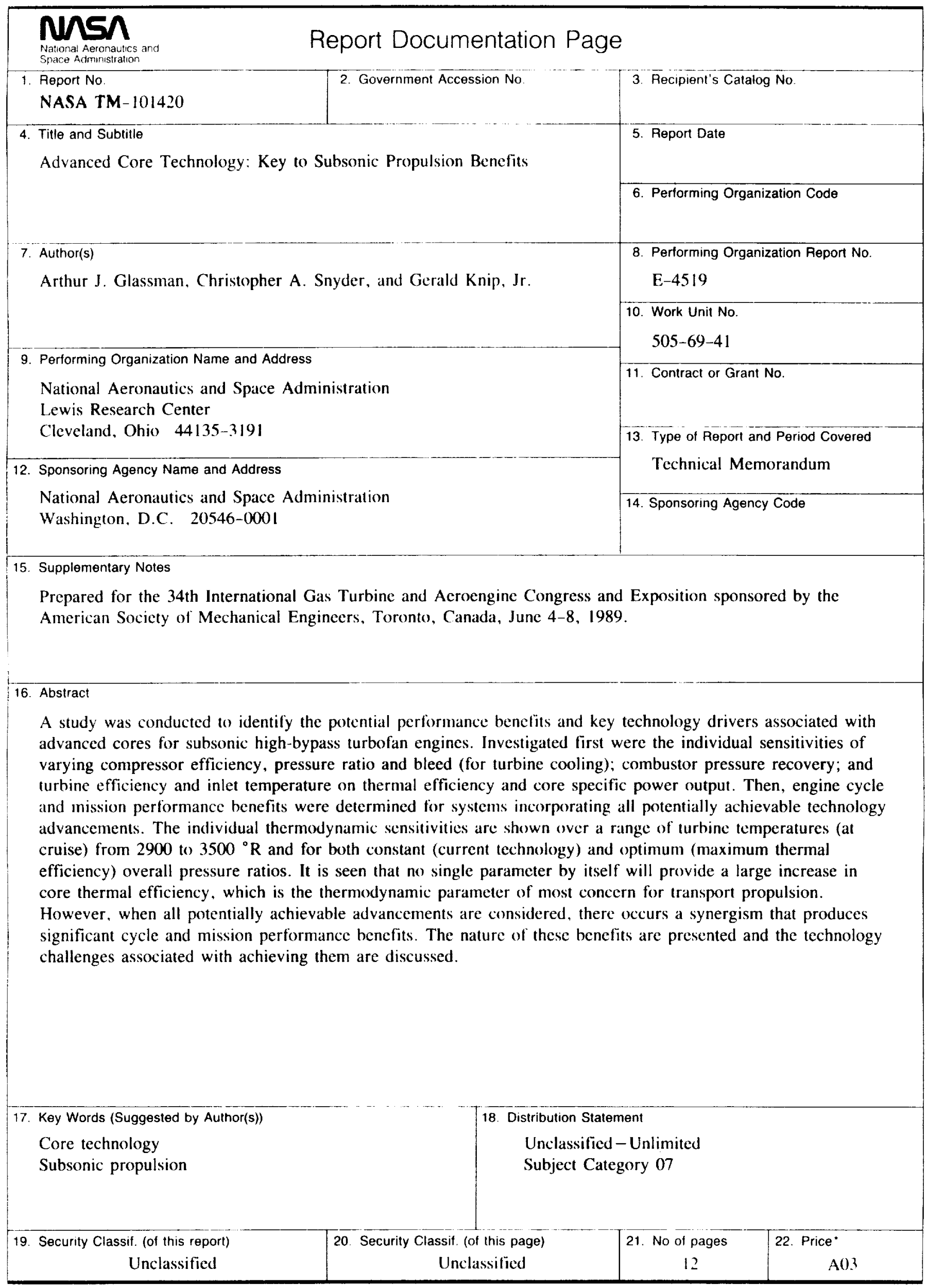

NASA FORM 1626 OCT в6 For sale by the Nationa! Technical Information Service. Springfield, Virginia 22161 

National Aeronautics and

Space Administration

Lewis Research Center

Cleveland Ohio 44135

Onciel Bushoss

Ponaty for Pitvato Uso $\$ 500$
SECOND CLASS MAIL

ADDRESS CORRECTION REQUESTEO
|||||

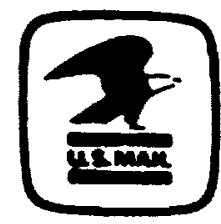

Postage and Foes Paid National Aeronautics and Spece Administration NASA-451 